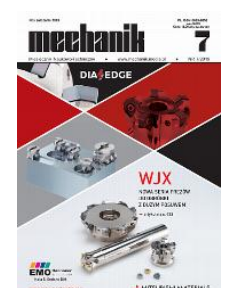

How to cite this article:

Author: Ireneusz Wróbel

Title of article: „FEM analysis of the hot stamping process of the B-pillar with patch”

Mechanik, No. 7 (2019)

DOI: https://doi.org/10.17814/mechanik.2019.7.49

\title{
FEM analysis of the hot stamping process of the B-pillar with patch
}

\section{IRENEUSZ WRÓBEL *}

Dr hab. inż. Ireneusz Wróbel, iwrobel@ath.bielsko.pl https://orcid.org/0000-0002-7587-0217 - Wydział Budowy Maszyn i Informatyki, Akademia Techniczno-Humanistyczna w Bielsku-Białej, Bielsko-Biała, Polska

The article presents the analysis of the hot stamping process of the B-pillar with patch. Special model of discrete blank and patch has been developed, taking into account the welded connection and two types of contact elements. The simulation of the hot stamping process was carried out and the simulation results were developed. The conclusions were formulated.

KEYWORDS: hot forming, B-pillar, FEM simulation

\section{Introduction}

New generation passenger car designers strive to reduce the body weight as much as possible. This trend is associated with the reduction of exhaust emissions of cars with internal combustion engines and balancing the mass of batteries in electric cars. At the same time, the body of a modern car must meet high requirements for the safety of the driver and passengers. Selected body parts, directly responsible for the safety of the driver and passengers, are designed so that during a collision they deform as expected by the designer and absorb the energy of a collision. An example of such an element is the B-pillar of a car body, located between the front and rear doors of the car body and designed to absorb side impact energy. This element is most often produced in the hot stamping technology [1].

The B-pillar of a modern car has zones of varying rigidity. They can be obtained in several ways. One of them is welding a flat pad with a flat patch and shaping them together in the hot stamping process. This results in greater B-post rigidity in the area of the patch.

FEM analyses of the hot stamping process with patch described so far in the literature, did not take into account the contact phenomena occurring between the patch and the form, as well as welded joints [2]. In discrete models, the connection between the form and the patch was modeled as bonded contact, thus the patch was permanently attached to the form and was unable to move relative to the form.

The aim of the research presented in this paper was to compare the results of simulation of the hot pressing process of the B-pillar, taking into account different ways of modeling the interaction of the form with the patch (two different types of contact elements). As part of the research work, CAD models and discrete FEM models of the form and patch were prepared, as well as CAD models and discrete FEM models of die working surfaces carrying out the hot stamping process.

\section{Construction of CAD and discrete models for the purpose of analysis}

Fig. 1 shows the CAD model of the B-pillar, which has been analyzed. This pillar is made of $2.2 \mathrm{~mm}$ thick sheet metal and has a $1.6 \mathrm{~mm}$ thick patch. The patch is connected to the pillar by means of welding joints at 12 points, as shown in fig. 2 .

Firstly, the CAD model of the tool was developed based on the B-pillar surface model. This model was imported into the PamStamp software and based on it, discrete matrix, punch and clamp models were built (fig. 3). The tools were divided into four-node, rigid finite elements of the Shell 4 type. 


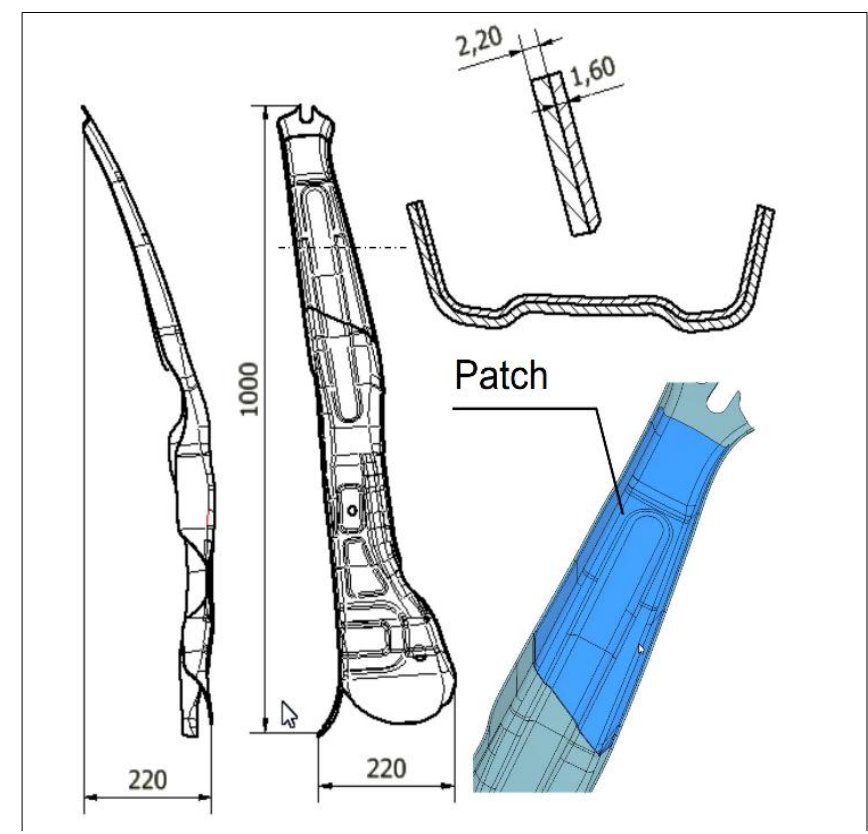

Fig. 1. CAD model of B-pillar

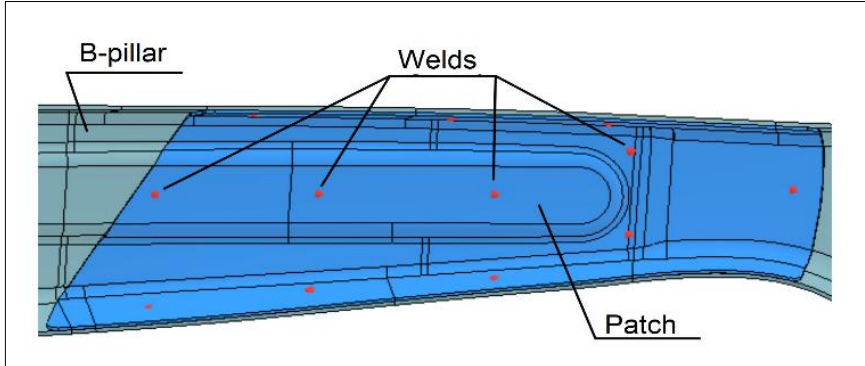

Fig. 2. Patch connected to the B-pillar with welds

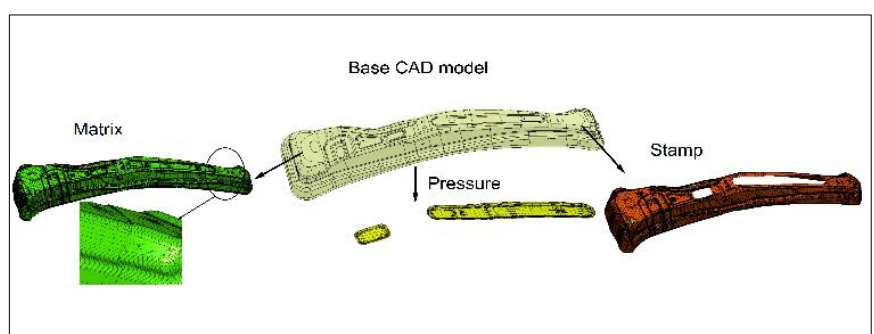

Fig. 3. Base model of the tool and discrete models of the matrix, punch and clamp

Then, the shape of the form and patch was determined, and the coordinates of 12 points, where the welds are located, were calculated (fig. 4). A specialized NX software module was used for this purpose. In the PamStamp system [5], a discrete model of the form with patch was developed. Two types of contact were defined between the form and the patch: bonded contact and friction contact $(\mu=0.4)$.

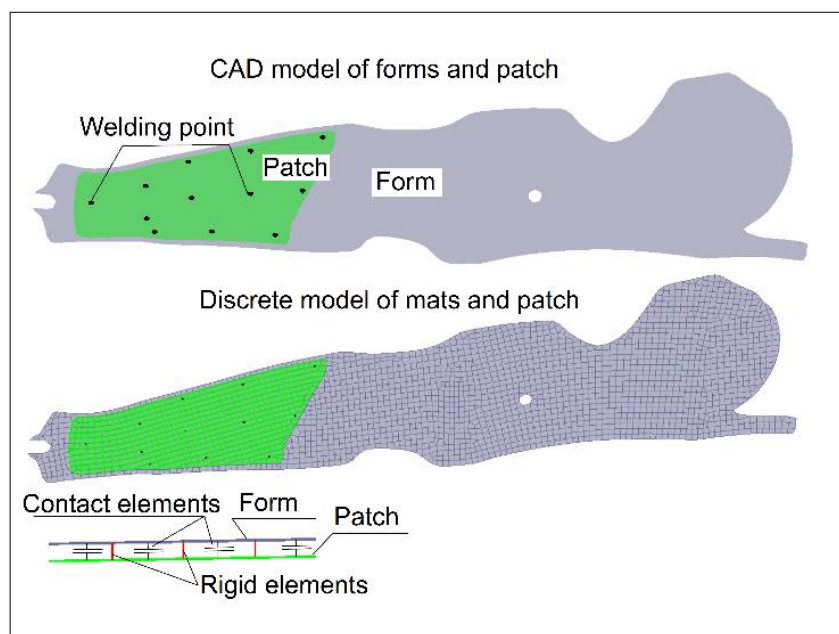

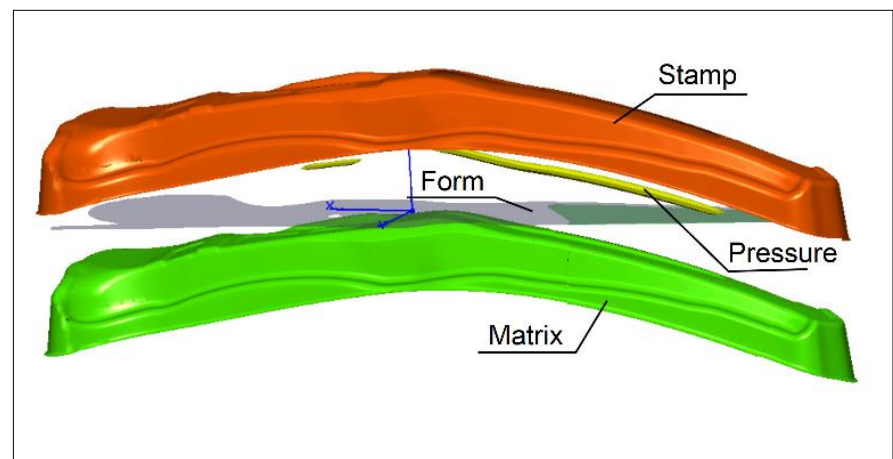

$\triangle$ Fig. 5. Discrete model of the tool

$\checkmark$ Fig. 4. Discrete model of the form with patch - with contact elements and rigid elements

Welded joints in the model taking into account contact with friction were modeled as a one-dimensional rigid joint between the discrete model of the patch and form. In the model with bound contact, there was no need to model welded joints, because the form and patch are permanently connected.

The form and patch were divided into four-node, flexible finite elements of the Shell 4 type. It was assumed that the mesh could be compacted four times in places where a large change in shape occurs during simulation of the hot stamping process. Tool elements - punch, matrix and clamp - were modeled using flat, rigid, four-node Shell 4 elements. As a result, a tool and form model was created (fig. 5).

The tool kinematics and hot pressing parameters were also defined. The process of pressing the B-pillar takes place in two sequences: first, the clamp closes the form on the matrix, and then the punch, moving towards the matrix, shapes the entire molding. It was assumed that the temperature of the mold before the pressing process is equal to $750^{\circ} \mathrm{C}$, and the temperature of the tools $-100{ }^{\circ} \mathrm{C}$. The discrete model was analyzed in the PamStamp software. 


\section{Analysis results}

Basic results of the analysis of the hot stamping process, examined by engineers dealing with this technology, are: contour thinning layers, FLD contouring layers, contouring layers of hardness distribution and martensite. Fig. 6 presents contour lines and histograms of extrusion thinning for models with contact and friction contact. In the model with friction, in the area where the patch is located, slightly larger areas with a higher thinning value, but not exceeding the critical values for the steel, from which the B-pillar is made (15\%), can be observed.

Fig. 7 presents contour lines and FLD histograms. They illustrate the risk of wrinkles and cracks, which are very similar for both analyzed models. There was no risk of cracks.

Fig. 8 presents contour lines and HV hardness histograms. For both analyzed models, the hardness of the molding in its entire volume exceeds the required value of $400 \mathrm{HV}$. In the model with bound contact, in the area where the patch is located, the hardness is lower (approximately $475 \mathrm{HV}$ ) than in the model with friction contact (approximately $500 \mathrm{HV}$ ).

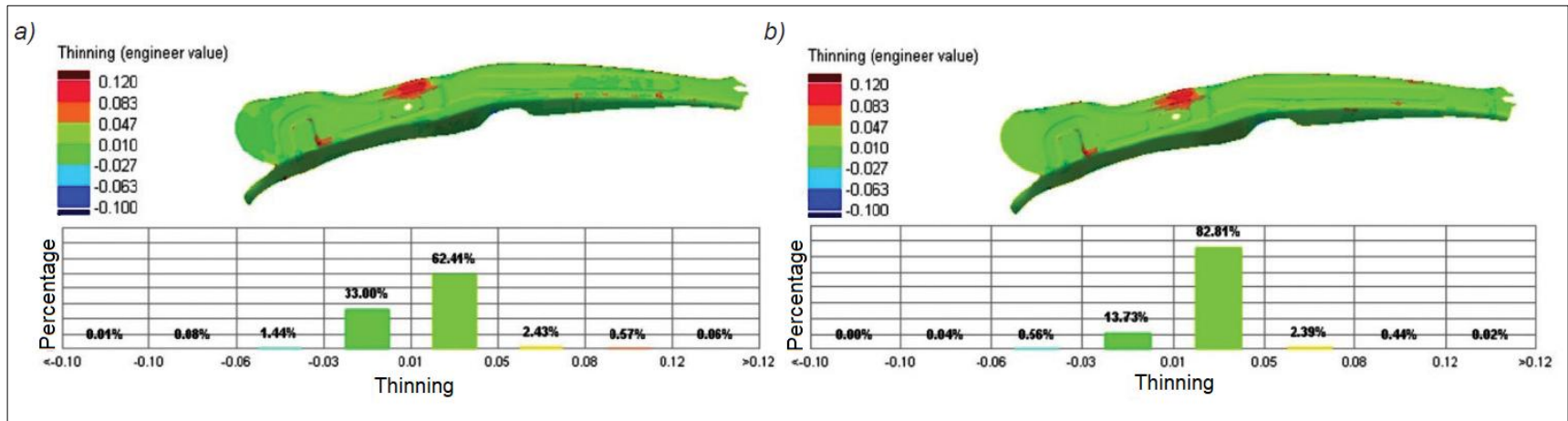

Fig. 6. Contour lines and extrusion thinning histograms for models: $a$ ) with bound contact, $b$ ) with friction contact

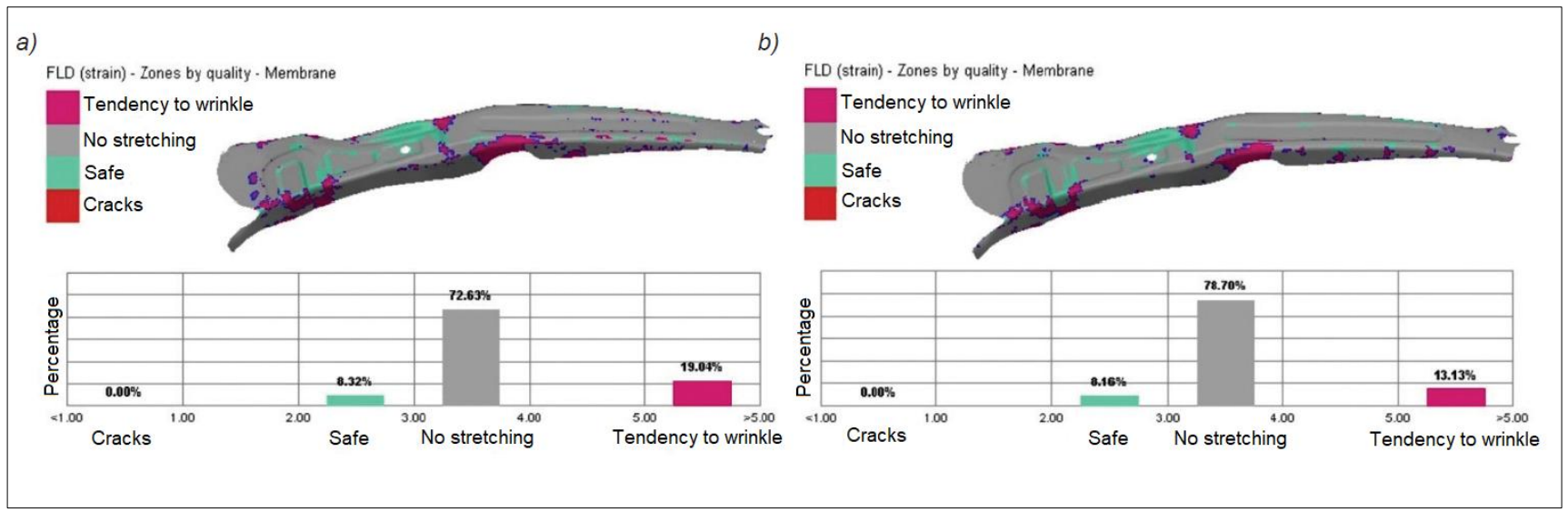

Fig. 7. Contour lines and FLD histograms of moldings for models: $a$ ) with bound contact, $b$ ) with friction contact

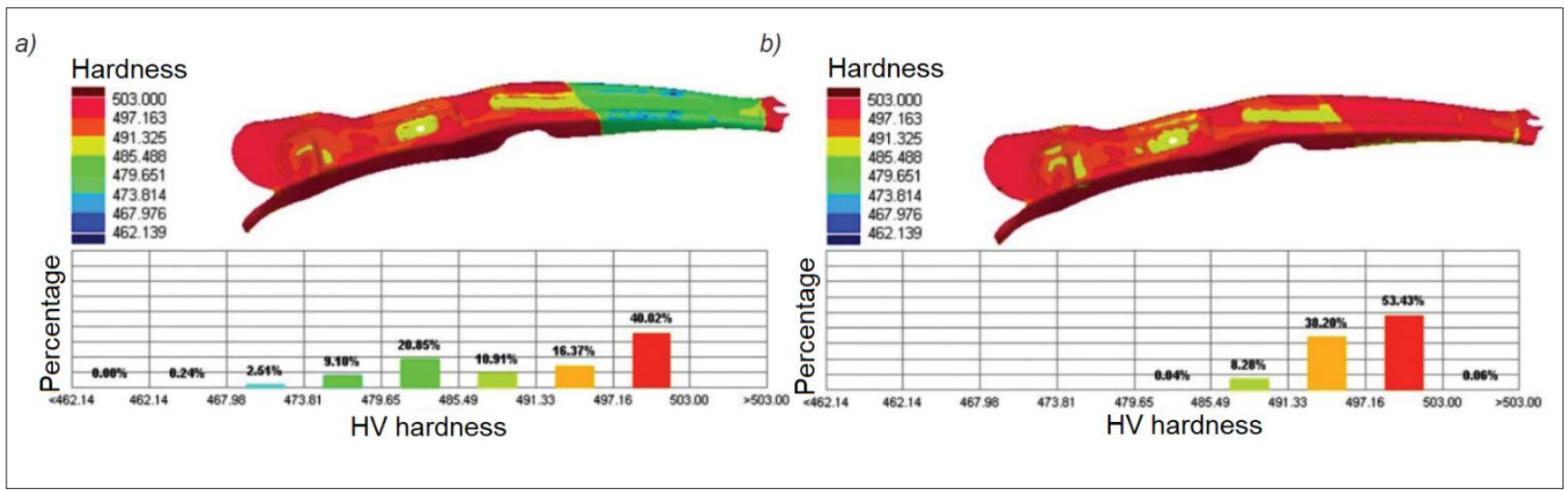

Fig. 8. Contour lines and HV histograms of moldings for models: $a$ ) with bound contact, $b$ ) with friction contact 
To check how the form with patch behaves when they are connected to each other only in two points, an additional model was made. The interaction of the patch with the form was modeled as contact with friction. Fig. 9 shows results of deformation of the form with the patch during its contact with the pressure for models: with bound contact and contact with friction and two welds. It can be seen that the model with friction contact allows for taking into account the phenomenon of detachment and displacement of the patch relative to the form, especially when there is too little weld.

a)

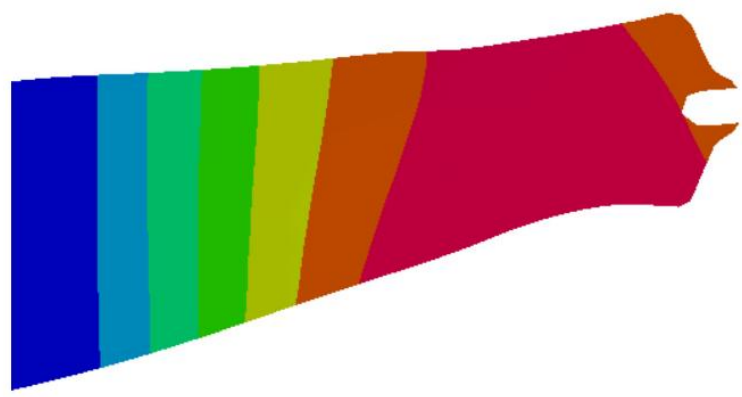

b)

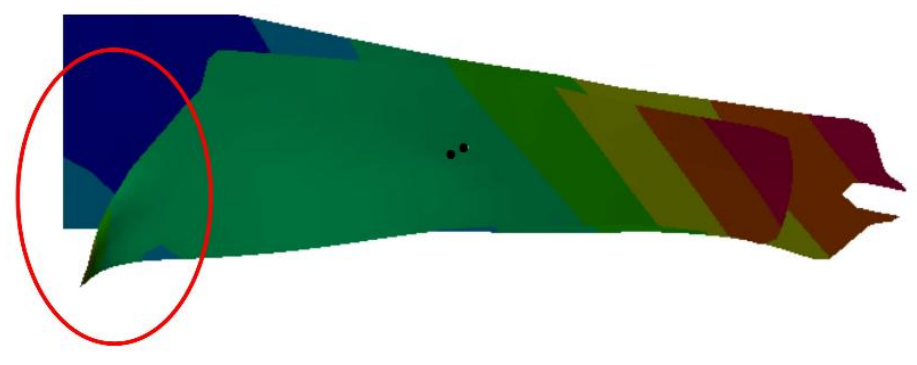

Fig. 9. Form deformation for models: $a$ ) with bound contact, $b$ ) with friction contact and welds

\section{Conclusions}

- The greatest impact of the method of modeling the contact between the form and the patch can be observed when analyzing deformation of the form and the patch during the pressing process. Model with friction contact allows for separation and displacement of the patch relative to the form. Due to this, it is possible to optimally select the number and position of welds between the form and the patch, ensuring the correct course of forming the mold during the hot stamping process. Too few welds or their improper arrangement may cause uncontrolled movement of the patch relative to the form during the molding process, which in turn, may cause defects in the form of patch crush.

- The effect of modeling the contact between the form and the patch on the results of thinning and FLD is not great. Slightly larger effect was observed in the case of contour lines and hardness histograms and martensite. The mold with bound contact in the patch areas has slightly lower hardness and lower martensite content compared to the mold, the model of which included contact with friction. It should be emphasized that these lower values do not exceed the limit levels recommended in hot stamping processes.

- In FEM simulations of the process of stamping car body elements, consisting of a form and an patch welded together at several points, discrete models should be used, in which the interaction of the form with the patch is modeled using contact elements with friction, and welds - using rigid, one-dimensional finite elements. Such models are more versatile and allow to take into account more phenomena that can occur when shaping the mold.

\section{REFERENCES}

[1] Chengxi L., Zhongwen X., Weili X., Zhenjun H., Debin S. "Hot stamping of patchwork blanks: modelling and experimental investigation". International Journal of Advanced Manufacturing Technology. 92, 15 (2017): 2609-2617, https://doi.org/10.1007/s00170-017-0351-9.

[2] Ping H., Liang Y., Bin H. "Hot Stamping Advanced Manufacturing Technology of Lightweight Car Body". Springer, 2017. Google Scholar.

[3] Merklein M., Johannes M., Lechner M., Kuppert A. "A review on tailored blanks - Production, applications and evaluation". Journal of Materials Processing Technology. 214, 2 (2014): 151-164, https://doi.org/10.1016/j.jmatprotec.2013.08.015.

[4] Kashani H., Kah P. "Laser overlap welding of Zn-coated steel on aluminum alloy for patchwork blank applications in the automotive industry". Reviews on Advanced Materials Science. 40, 3 (2015): 295-302, https://www.researchgate.net/publication/291457576 LASER OVERLAP WELDING OF ZnCOATED_STEEL_ON_ALUMINIUM_ALLOY_FOR_PATCHWORK BLANK APPLICATIONS IN_THE_AUTOMOTIVE_INDUSTRY.

[5] PamStamp help system. 